\title{
Gas-turbine Diagnostics Using Artificial Neural-networks for a High Bypass Ratio Military Turbofan Engine
}

\author{
R B Joly, S O T Ogaji*, R Singh, and S.D. Probert \\ School of Engineering, Cranfield University, Bedfordshire MK43 OAL, UK
}

\begin{abstract}
The Tristar aircraft, operated by the Royal Air Force, fly many thousands of hours per year in the transport and air-to-air refuelling roles. A large amount of engine data is recorded for each of the Rolls-Royce RB211-524B4 engines: it is used to aid the maintenance process. Data are also generated during test-bed engine ground-runs after repair and overhaul. In order to use recorded engine data more effectively, this paper assesses the feasibility of a pro-active engine diagnostic-tool using artificial neural networks (ANNs). Engine-health monitoring is described and the theory behind an ANN is described. An engine diagnostic structure is proposed using several ANNs. The top level distinguishes between single-component faults (SCFs) and doublecomponent faults (DCFs). The middle-level class includes components, or component pairs, which are faulty. The bottom level estimates the values of the engineindependent parameters, for each engine component, based on a set of engine data using dependent parameters. The DCF results presented in this paper illustrate the potential for ANNs as diagnostic tools. However, there are also a number of features of ANN applications that are user-defined: ANN designs, the number of training epochs used; the training function employed, the method of performance assessment; and the degree of deterioration for each engine-component's performance parameter.
\end{abstract}

\section{Abbreviations and Nomenclature}

ANN Artificial Neural network

BPR Bypass ratio

DCF Double-component Fault

EDMS Exhaust-debris monitoring system

EFH Engine Flying Hour

EGT Exhaust-Gas’ Temperature

\footnotetext{
* Corresponding author
} 


\begin{tabular}{|c|c|}
\hline EHM & Engine-Health Monitoring \\
\hline EHUMS & Engine health and usage management system \\
\hline GA & Genetic Algorithm \\
\hline GPA & Gas-path Analysis \\
\hline $\mathrm{HCF}$ & High Cycle-Fatigue \\
\hline $\mathrm{HP}$ & High pressure \\
\hline HPC & High-pressure compressor \\
\hline HPT & High-pressure turbine \\
\hline ICM & Influence Coefficient Matrix \\
\hline IDMS & Inlet-debris monitoring system \\
\hline IP & Intermediate pressure \\
\hline IPC & Intermediate-pressure compressor \\
\hline IPT & Intermediate-pressure turbine \\
\hline ISA & International standard-atmosphere \\
\hline LP & Low pressure \\
\hline LPC & Low-pressure compressor \\
\hline LPT & Low-pressure turbine \\
\hline MSE & Mean Square Error \\
\hline $\mathrm{N}$ & Relative spool speed \\
\hline OEM & Original Equipment-Manufacturer \\
\hline OLS & Off-line sensor \\
\hline OPR & Overall Pressure-Ratio \\
\hline $\mathrm{P}$ & Pressure (bar) \\
\hline ROI & Return on Investment \\
\hline
\end{tabular}




$\begin{array}{cl}\text { SCF } & \text { Single-component Fault } \\ \text { SCG } & \text { Scaled Conjugate Gradient } \\ \text { SFC } & \text { Specific Fuel Consumption } \\ \text { SLS } & \text { Sea-level static } \\ \text { T } & \text { Temperature }(\mathrm{K}) \\ \text { TET } & \text { Turbine's Entry-Temperature } \\ \mathrm{W}_{\mathrm{f}} & \text { Rate of fuel flow }(\mathrm{Kg} / \mathrm{s}) \\ \Gamma & \text { Flow capacity } \\ \eta & \text { Efficiency }\end{array}$

\section{Glossary}

Axon

Dendrites

Design Point

Neuron

Synapse
Long nerve fibre that conducts impulses away from the cell body of the neuron

Extension of a nerve cell that conducts impulses from adjacent cells inward toward the cell body

The optimal point determined by a number of engine parameters where an engine is intended to operate most of the time A specialised cell for conduction nerve impulses The junction across which a nerve impulse passes from an axon terminal to a neuron

\section{Introduction}

The art of engine-health monitoring (EHM) is becoming more complex as the array of technologies available increases. However, core-engine performance monitoring techniques continue to be the prime diagnosis tool, whereby the analysis of the gasturbine's gas-path parameters provides information about the degradation severity of each gas-path component [1]. In addition, other technologies such as wear-debris analysis and vibration monitoring also remain key techniques of EHM. As computing power continues to increase and more-mathematical tools become available for the EHM of gas-turbines, the available artificial intelligence grows in complexity.

The cost of an aircraft's diversion in flight for a technical reason is potentially high. The resulting loss of passenger confidence leading to a longer-term reduced revenue, shortterm costs associated with the diversion (e.g. hotels, transport) and operational inconvenience (e.g. the aircraft being unavailable at the required airport for the next planned trip, as well as the disruptions to crew rosters and aircrew duty times) can be very expensive. The consequences incurred in the ditching of a plane or a catastrophic failure are even higher. In addition, for military aircraft, the results of direct mission failure and adverse effects on other aircraft can be very grave 
In order to achieve excellent in-service use of modern gas-turbine aero-engines, they should incorporate capable performance-monitoring systems. However, the ability of such a diagnostic system is reliant upon complying with the following criteria:

- Well-defined reliability goals: for instance, Rolls-Royce have sought to improve despatch reliability of the Boeing 767 from $99.91 \%$ to 99.95\% by incorporating EHM on the RB211-535E4 [2].

- Physical-space limitations for system hardware.

- A well-defined system specification: for example, definition of the end user as either maintenance personnel, aircrew or original equipment manufacturer.

- Format of information output:- cockpit indication, ground maintenance trending by operator or third-party telemetric monitoring.

- Cost.

- Data-processing procedure.

- Changes to the above criteria depending on whether or not the EHM system is designed-in or retrofitted.

\section{Engine-Health Monitoring}

\subsection{Overview}

The specialist EHM discipline, of is a desirable aspect of modern aero-engine gasturbine management, provides engine-fleet managers with a tool for the pro-active management of assets.

The definition of the word health is 'a state of being well and free from illness; a condition of the body'. This immediately sets EHM apart from the concept of usage, which is 'the manner of using or treating something; customary practice'. Nevertheless, there is often a misunderstanding of the difference between an EHM system and Engine Health and Usage Management System (EHUMS): EHM provides an assessment of the current state of an engine and EHUMS is both an assessment of the current state and the common use of the engine.

According to Green [3], a form of 'sensing, learning and reasoning EHM system is the cornerstone or more importantly the missing link between our current diagnostic confused state, and a status of a true diagnostic with prognostic, or knowledge with wisdom capability'. The message was that 'smart' EHM was required and led to the evolution of EHM/diagnostics towards EHM/diagnostics/ prognostics.

\subsection{Traditional Forms of EHM}

These have been described extensively by Li [1], Alcock [4], Theriault [5], Escher [6], and Powrie and Fisher [7]. EHM itself has long been recognised as only a part of an engine-monitoring system (EMS); an EMS includes considerations of the associated people, equipment and procedures involved in gas-turbine engine monitoring [8]. 


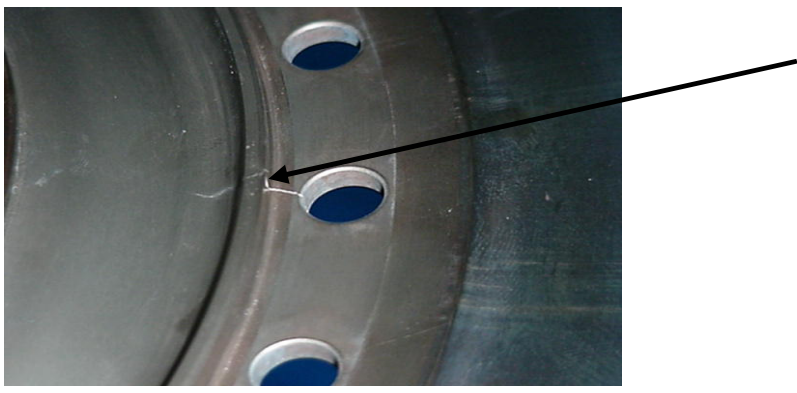

Crack

Figure 1 - Bolthole crack in the F-100 stage 10 disc

The EHM process, must be able to assess the performance of the engine and also its mechanical integrity. Figure 1 illustrates the type of damage that needs to be detected. The challenge is usually complicated by the requirement to conduct the EHM with the engine 'on wing', or installed. EHM can be divided into a number of technologies: wear-debris analysis, gas-path performance, visual inspection, vibration analysis and life usage. Table 1 summarises, the technologies available and the types of healthassessment techniques utilised.

Table 1 - Summary of traditional EHM methods

\begin{tabular}{|c|c|c|c|}
\hline EHM Method & Assessment based on: & Monitoring Technique & Features \\
\hline $\begin{array}{c}\text { Wear Debris } \\
\text { Analysis }\end{array}$ & $\begin{array}{l}\text { Measurement of mechanical } \\
\text { debris arising due to wear of } \\
\text { components such as } \\
\text { bearings and shafts }\end{array}$ & $\begin{array}{l}\text { Visual via magnetic } \\
\text { chip plug }\end{array}$ & $\begin{array}{l}\text { Rapid assessment } \\
\text { Trending }\end{array}$ \\
\hline $\begin{array}{c}\text { Gas-path } \\
\text { Performance }\end{array}$ & $\begin{array}{l}\text { Monitoring of engine- } \\
\text { dependent parameters such } \\
\text { as pressures, temperatures } \\
\text { and spool speeds - } \\
\text { comparison with baseline } \\
\text { values and inference of } \\
\text { independent parameter } \\
\text { changes }\end{array}$ & Sensor based & $\begin{array}{l}\text { Trending } \\
\text { Unless linked to } \\
\text { diagnostic system, } \\
\text { requires manual } \\
\text { assessment of data }\end{array}$ \\
\hline Visual Inspection & $\begin{array}{l}\text { Non-destructive external } \\
\text { and internal visual } \\
\text { inspection techniques (for } \\
\text { gas-path components) using } \\
\text { liquid penetrants, eddy } \\
\text { current, ultrasound, } \\
\text { radiography and/or lasers }\end{array}$ & $\begin{array}{l}\text { Human eye using } \\
\text { rigid/flexible } \\
\text { borescopes }\end{array}$ & $\begin{array}{l}\text { Rapid assessment } \\
\text { Engine may require } \\
\text { partial strip } \\
\text { Quality of } \\
\text { assessment is } \\
\text { highly dependent } \\
\text { upon the } \\
\text { experience of the } \\
\text { technician }\end{array}$ \\
\hline
\end{tabular}




\begin{tabular}{|c|c|c|c|}
\hline Vibration Analysis & $\begin{array}{l}\text { Monitoring of vibration } \\
\text { characteristics and } \\
\text { comparison of actual values } \\
\text { with baseline figures }\end{array}$ & Sensor based & $\begin{array}{l}\text { Rapid assessment } \\
\text { Quality of } \\
\text { assessment is } \\
\text { highly dependent } \\
\text { upon the } \\
\text { experience of the } \\
\text { technician }\end{array}$ \\
\hline Life Usage & $\begin{array}{l}\text { Life monitoring of gas- } \\
\text { turbine systems; life } \\
\text { dependent upon creep and } \\
\text { low cycle fatigue }\end{array}$ & Sensor based & $\begin{array}{c}\text { Prediction and } \\
\text { prevention of early } \\
\text { failure } \\
\text { Life calculation } \\
\text { based on mission } \\
\text { profile; can be } \\
\text { subjective }\end{array}$ \\
\hline
\end{tabular}

Most EHM processes combine the technologies available; for instance a gas-path performance assessment might be confirmed or supported by a vibration analysis. Gaspath performance monitoring techniques include both linear and non-linear gas-path analyses (GPAs).

\subsection{Emerging Forms of EHM}

Two examples are shown in Table 2. The state of an engine can be inferred by monitoring the electrostatic charge of particles entering, travelling through or departing from an open-flow system. Electrostatic technology has the ability to classify fault severity in real-time with an early-warning capability.

\section{Table 2 - Summary of emerging EHM methods}

\begin{tabular}{|c|c|c|c|}
\hline EHM Method & Assessment based on: & Monitoring technique & Features \\
\hline Electrostatics & $\begin{array}{l}\text { Monitoring the electrostatic } \\
\text { characteristics of debris in } \\
\text { different parts of the engine: } \\
\text { Inlet-Debris Monitoring } \\
\text { System (IDMS) } \\
\text { Exhaust-Debris Monitoring } \\
\text { System (EDMS) } \\
\text { Oil-Line Sensor (OLS) }\end{array}$ & Sensor based & $\begin{array}{c}\text { Real-time: } \\
\text { Early warning of } \\
\text { faults } \\
\text { Severity of fault } \\
\text { predicted so } \\
\text { benefiting the } \\
\text { maintenance } \\
\text { operation } \\
\text { OLS can detect } \\
\text { non-metallic debris }\end{array}$ \\
\hline
\end{tabular}




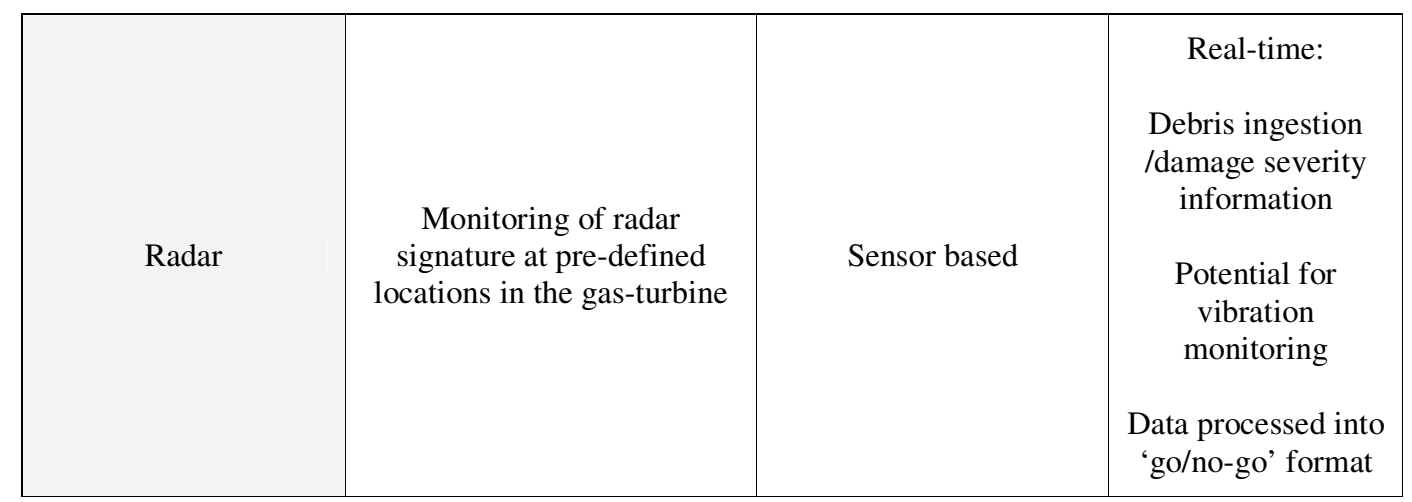

Radar technology offers similar benefits to electrostatics, but has the added advantage that vibration monitoring could be applied simultaneously. As EHM costs require careful control, the use of multi-function of a single-sensor is an appealing attribute.

\section{Artificial Neural networks}

\subsection{Background}

A neural network is a system composed of many simple processing-elements, operating in parallel and whose function is determined by the network structure, connection strengths: the processing is performed at computing elements or nodes. Neural network designs are inspired by the architectures of biological nervous systems, which use many simple processing elements, operating in parallel, to obtain high computation-rates. These mathematical neuron models are commonly referred to as artificial neural networks (ANNs). Unlike the classical digital-processing techniques used by most computers, ANNs possess the ability to [9][10]:

- Perform parallel processing of data

- Cope with noisy data

- Cope with system faults

- Adapt to different circumstances

Digital computers process data serially in real-time, but the downside is that they have to prioritise tasks. However, ANNs process data asynchronously in real-time, which means they can cope with multiple simultaneous inputs without detriment to the quality of the output.

The human nervous-system was partially understood by the Greeks in 200 BC. By the late 1800 s, sensory processing was already being described as a switching network. In 1957, Rosenblatt conceived the 'perceptron' neural network [11], i.e. a relatively simple network 'whose weights and biases could be trained to produce a correct target vector when presented with the corresponding input vector' [12]. The limitations of the perceptron model were highlighted in 1968 and the evolution of neural networks slowed until the 1980s. Understanding of neural networks improved rapidly thereafter [11]. 
ANNs can mean different things to different people. Mathematicians and physicists consider neural networks to be dynamic systems via which problems are solved through relaxation processes. In each such network, the energy state moves towards an energy minimum that corresponds to a solution. The Hopfield network is a classic example [11]. Biologists and psychologists, however, see ANNs as a means of implementing a variety of cognitive and sub-cognitive functions, as interpreted by Grossberg [11]. Finally, there is the understanding of ANNs by an engineer, who will identify the most appropriate optimal network design, and apply it to the task to be solved. The common theme throughout the different interpretations, however, is that ANNs are dynamic, i.e. possess the ability to change with time.

\subsection{The Human Brain}

ANNs are modelled on the structure and behaviour of neurons and synapses in the human brain. Therefore it is desirable to understand the operation of a human neuron prior to investigating the structure of an ANN. A neuron consists of a cell body with a number of dendrites and a single axon. The dendrites supply a means of inputting the signals from other neurons into the cell body and the axon provides a means of outputting the signal from the cell body to other neurons. The architecture is shown in Figure 2.

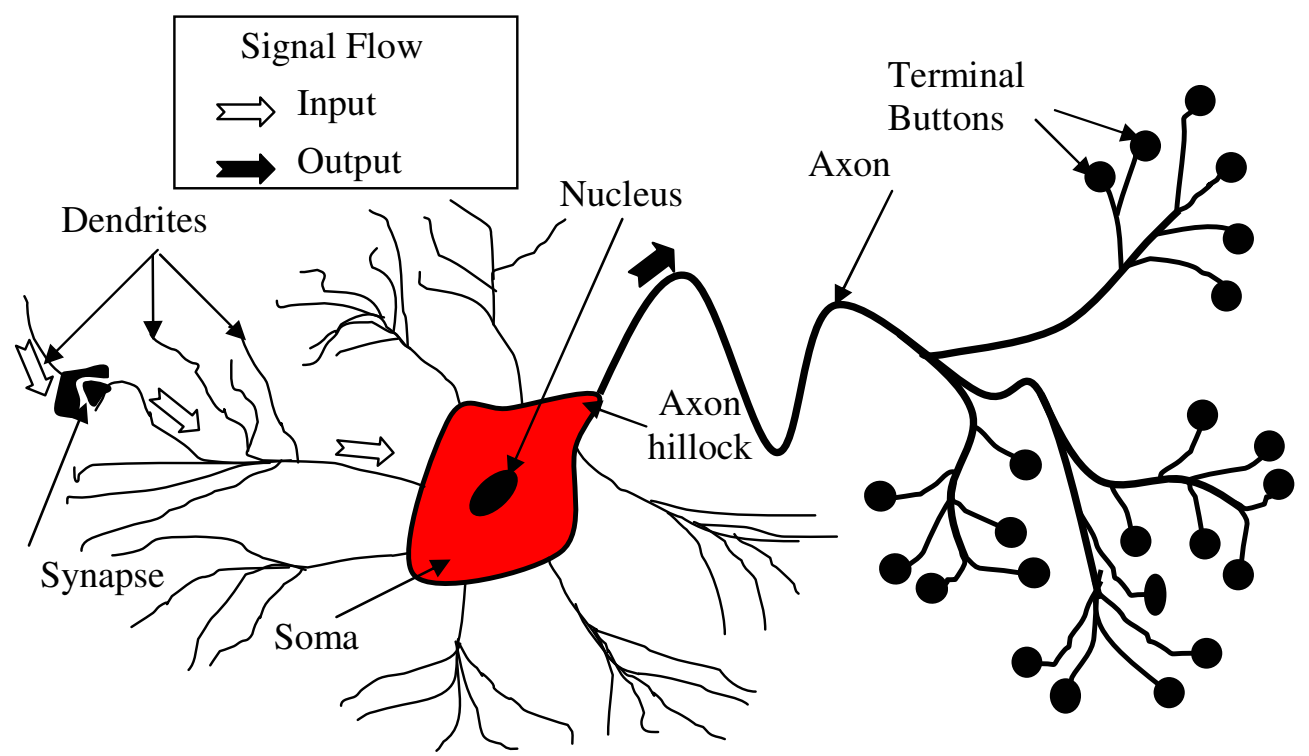

Figure 2 - The human neuron

A neuron does nothing unless the collective influence of all its inputs reaches a threshold level, above which the neuron produces a full-strength output in the form of a narrow pulse that proceeds from the cell body, down the axon, and enters the axon branches. The neuron is said to "fire" in such an event [13]. The dendrites can provide many inputs but the axons supply far fewer outputs. Between an axon and the dendrite 
of an adjacent neuron, there exists a synapse, i.e. a link consisting of a pre-synaptic membrane and a post-synaptic membrane. Between these membranes, there is a synaptic gap. As a signal leaves a neuron via the axon, a voltage is induced across the synaptic gap and acts as a neuro-transmitter providing an adjacent dendrite with a neuro-signal.

The stimulation at a synapse can either encourage or discourage the neuron to fire. The description so far has been for one or two neurons. Before discussing ANNs, one should realise that there are $\sim 10^{11}$ neurons in a human brain and a single neuron can receive inputs from as many as $10^{5}$ synapses [13].

\section{Diagnostics for a High BPR Turbofan}

\subsection{Data Generation}

In the absence of real engine-data, it was necessary to use a gas-turbine performance model to generate the required data for application to a neural network. For this purpose, a simulation program called "Turbomatch", developed at Cranfield University, was used. However, the first step in setting up the diagnostic process was to decide on the design-point at which the work was to be conducted. Given that the performance data were available for take-off under ISA SLS conditions, it was chosen as the design point. The second step was then to establish the performance parameters required to simulate the behaviour of the appropriate version of the engine: i.e.

- TET

- EGT

- Compressor's Pressure-Ratio

- Thrust

- Mass Flow-Rate

- OPR

It was then intended to modify the Turbomatch simulation so as to achieve the desired take-off thrust along with the appropriate values of the TET, EGT, compressor pressureratios and OPR. However, it soon became apparent that, to achieve the desired result, modifying the model had to be an iterative process. Hence, many of the parameters ended up with significant percentage differences between the provided and actual values. Thrust and TET are arguably the most important to keep as close to reality as possible: thrust so as to maintain the specified value and TET at a level that does not exceed the cooling ability and 'lifing' criteria. The percentage difference values were an undesirable feature of the model, since the errors could be of the same magnitude as those of the faults that were ultimately being simulated.

In order to assess the health of a gas-turbine engine and ultimately provide a diagnosis concerning any detected faults, it is desirable to have data that relate dependent (engine measurements) to independent (performance) parameters under a number of conditions. 
The Turbomatch program has the ability to simulate the behaviour of an engine as well as the effects of implanted faults in its engine components, for instance a reduction in component efficiency or mass flow capacity. Turbomatch was therefore used to generate data for the effects of various engine-component deteriorations.

Table 3 - Planned double-component independent parameter deviations

\begin{tabular}{|c|c|c|c|c|}
\hline \multirow{2}{*}{$\begin{array}{c}\text { Component Pair } \\
\text { Components 1+2 }\end{array}$} & \multicolumn{2}{|c|}{ Component 1 Deviations } & \multicolumn{2}{c|}{ Component 2 Deviations } \\
\cline { 2 - 5 } & $\% \eta$ & $\% \Gamma$ & $\% \eta$ & $\% \Gamma$ \\
\hline IPC + HPC & -5 & -15 & -3 & -9 \\
\hline IPC + HPT & -5 & -15 & -5 & +10 \\
\hline IPC + IPT & -5 & -15 & -2.5 & +5 \\
\hline
\end{tabular}

The relationship between physical degradation and simulated degradation is realised by choosing certain ratios between component efficiency and mass-flow capacity degradations. The exact ratios chosen can be open to some individual subjectivity and so it was worthwhile establishing the values of their ratios commonly concluded from previous research [6][14]. The ratio of efficiency to mass flow capacity chosen for component 1 in all the pairs and component 2 in the IPC+HPC pair was 1:3. This represented the effect of compressor fouling [6]. The ratio of efficiency to mass flow capacity for component 2 in the IPC+HPT and IPC+IPT pairs was chosen to be 1:2, which is typical of the effect of erosion of the turbine [6]. See Table 3.

Some of the key factors that should be considered before attempting practical network training are included in Table 4: whilst there are other factors, many of the considerations will be common.

Table 4 - Factors to consider prior to ANN use

\begin{tabular}{|c|c|}
\hline Factor & Reason for consideration \\
\hline Key objective: fault approximation or classification & Must not lose sight of the main goal of the study \\
\hline Engine component to be investigated & $\begin{array}{l}\text { Can realistic data be generated or obtained for the } \\
\text { chosen engine component(s)? }\end{array}$ \\
\hline Number of data points to be generated or obtained & $\begin{array}{l}\text { Network training period is a function of the number } \\
\text { of points to be processed }\end{array}$ \\
\hline $\begin{array}{l}\text { Type of ANN design to be used throughout the } \\
\text { study }\end{array}$ & $\begin{array}{l}\text { Credible comparison of results with previous } \\
\text { conclusions }\end{array}$ \\
\hline Recommendations from previous studies & Avoidance of (i) duplication and (ii) wasted effort \\
\hline $\begin{array}{l}\text { Backstop date for completion of practical } \\
\text { investigation }\end{array}$ & $\begin{array}{l}\text { Allow enough time for analysis and discussion of } \\
\text { the derived data }\end{array}$ \\
\hline
\end{tabular}




\subsection{Strategy and Plan}

Previous studies demonstrate that ANNs, trained with simulated data representing engine degradation, can be used for diagnostic purposes [4]. Two respected sources for research have included a requirement to assess ANN performance when the engine suffers multiple-component faults [4][5]. Hence this study considered multiplecomponent faults, which occur commonly in gas-turbine aero engines. A plan was devised as shown in Figure 3.

Stage 1

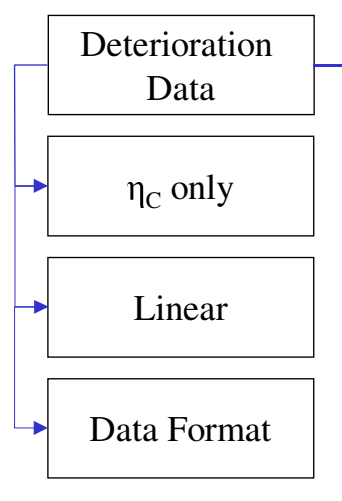

Stage 2

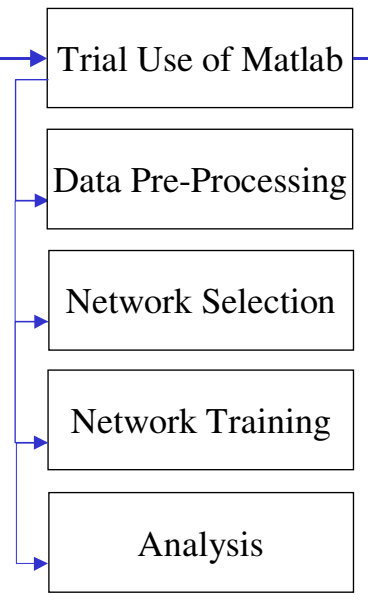

Stage 3

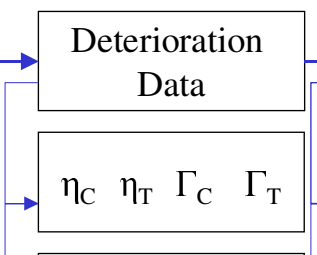

Linear and Non-Linear

Data Format

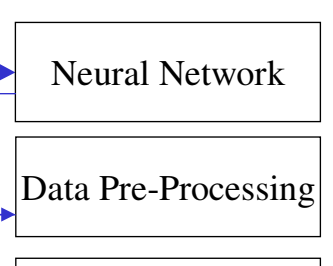

Network Selection

Network Training

Analysis

Figure 3 - The plan of the present research project

\subsection{Practical Implementation}

In order to train an ANN, 3 sets are required:

- Training data.

- Target outputs.

- Test data.

An ANN requires only raw data. The ANN does not need to know the intended use of the output and this is therefore an attractive feature, since the potential uses are limitless. For the reasons mentioned, the data sets are presented in "numbers-only" format and do not require any data labels. The engine data were initially mixed with a signal that was meant to represent sensor noise. The actual noise was generated randomly for each set of 11 engine parameters; the magnitudes employed were the same as those used for a sensor suite studied by Ogaji, et al [10] - see Table 5. 
Table 5 - Sensor's Noise Levels

\begin{tabular}{|c|l|c|}
\hline $\begin{array}{c}\text { Engine } \\
\text { Parameter }\end{array}$ & \multicolumn{1}{|c|}{ Description } & $\begin{array}{c}\text { Noise }+/ \text { - }(\% \text { of } \\
\text { range })\end{array}$ \\
\hline $\mathrm{N}_{1}$ & LP relative spool speed & 0.03 \\
\hline $\mathrm{N}_{2}$ & IP relative spool speed & 0.03 \\
\hline $\mathrm{N}_{3}$ & HP relative spool speed & 0.02 \\
\hline $\mathrm{P}_{3}$ & Fan's exit total-pressure (bar) & 0.10 \\
\hline $\mathrm{P}_{5}$ & LPC's exit total-pressure (bar) & 0.10 \\
\hline $\mathrm{T}_{3}$ & Fan's exit total temperature $(\mathrm{K})$ & 0.40 \\
\hline $\mathrm{T}_{5}$ & LPC's exit total temperature $(\mathrm{K})$ & 0.40 \\
\hline $\mathrm{T}_{10}$ & LPT's inlet temperature $(\mathrm{K})$ & 0.40 \\
\hline $\mathrm{T}_{12}$ & IPT's inlet temperature $(\mathrm{K})$ & 0.40 \\
\hline $\mathrm{T}_{13}$ & HPT's inlet temperature $(\mathrm{K})$ & 0.40 \\
\hline $\mathrm{W}_{\mathrm{f}}$ & Fuel flow (Kg/s) & 0.40 \\
\hline
\end{tabular}

Once the noise was superimposed, the data were normalised. The diagnostic structure is shown in Figure 4.

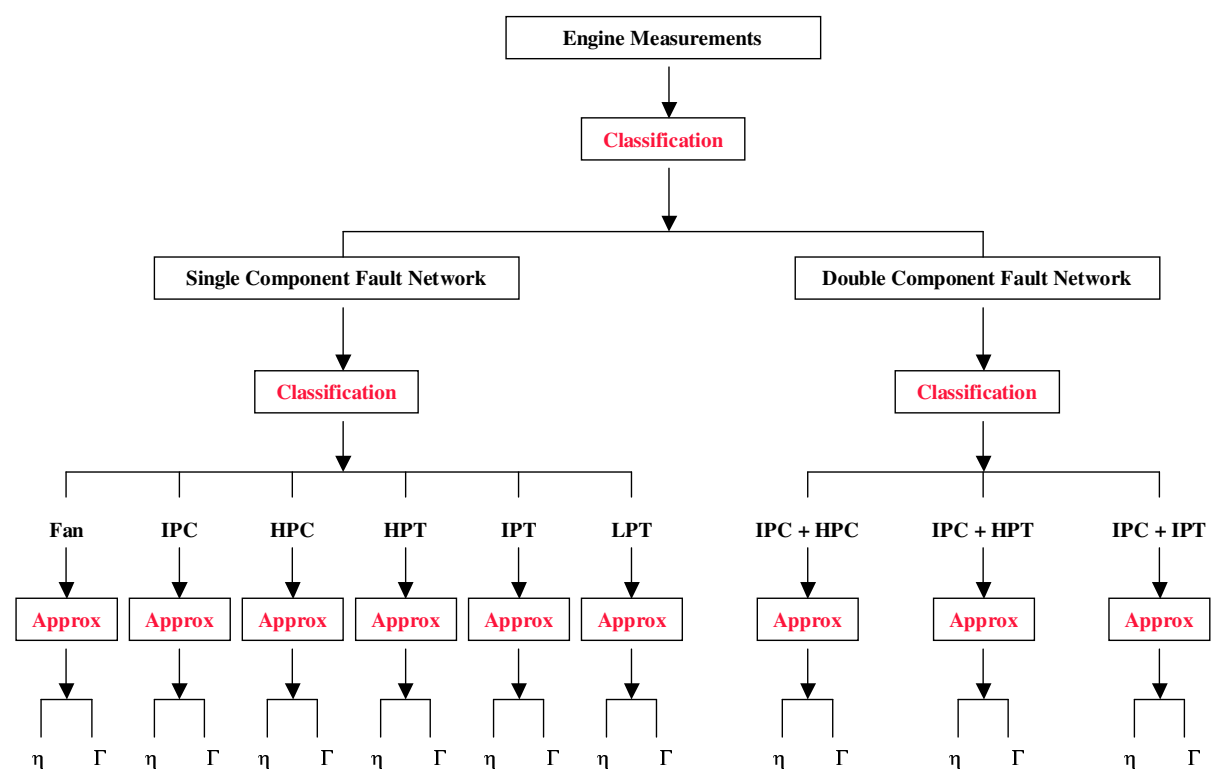

Figure 4 - The diagnostic structure 


\section{DCF Results}

Only DCF results are presented in this paper. Furthermore, only three pairs, out of a possible 15 fault combinations, are investigated.

The three ANNs, one for each DCF combination, were trained and tested: and Figure 5 shows the arising performance summaries for the investigated fault-quantification networks. The last line in the figure's title indicates the number of epochs considered, the number of neurons in the hidden and output layers of the defined network structure, the fault category and finally the type of training algorithm applied.

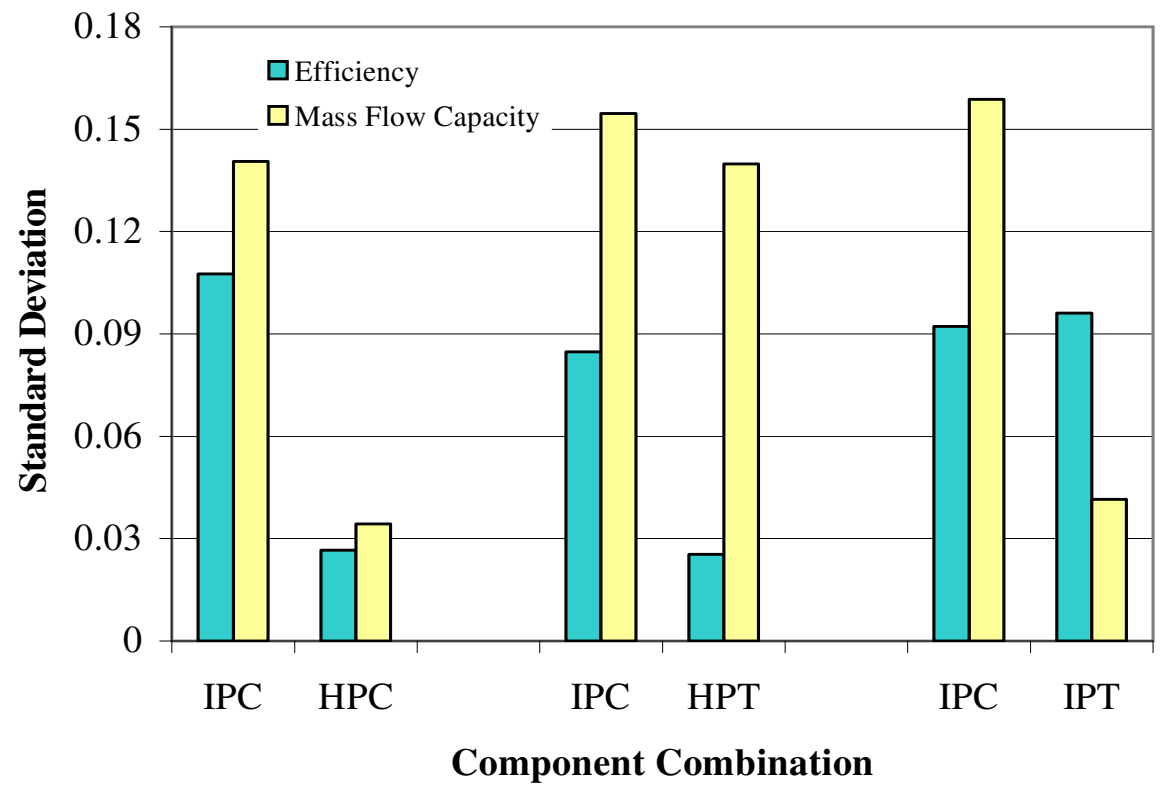

Figure 5 - Double-component network performance summary

- Standard deviation (absolute error)

- 1000 epochs/20_20_4/DCF approximation/SCG

The first observation is that the standard deviation is relatively low, especially when compared with the magnitude of the standard deviations for the single-component fault ANNs. However, the magnitude of the standard deviation for the double-component networks would be expected to be higher than for the single-component ones. Secondly, the IPC has a consistently poor comparative performance regardless of the pairing; although this is within the context of relatively low overall standard deviations.

Furthermore, the mean error for the IPC is relatively high. For instance, the lowest deviation for the IPC efficiency is $0.5 \%$ and therefore a mean error of 0.135 (see Figure 6) means that the spread of actual values for a nominal $0.5 \%$ could be 0.365 to 0.635. If the standard deviation of 0.105 (see Figure 5), is then taken into account, the spread of possible values for a nominal $0.5 \%$ degradation in IPC efficiency could be 0.26 to $0.74 \%$. This degree of accuracy represents a $50 \%$ possible variation on the nominal value. The accuracies for each component vary depending on the particular pairing, but an inspection of the standard deviation and mean error plots shows only a 
small variation in the value of the respective parameters. This basic assessment could be conducted for all the components: it illustrates 2 key findings:-

- The accuracy established may be unacceptable if the gas-turbine under investigation has very small degradations in efficiency.

- Considering either the standard deviation or the mean error in isolation is inadequate for assessing network performance.

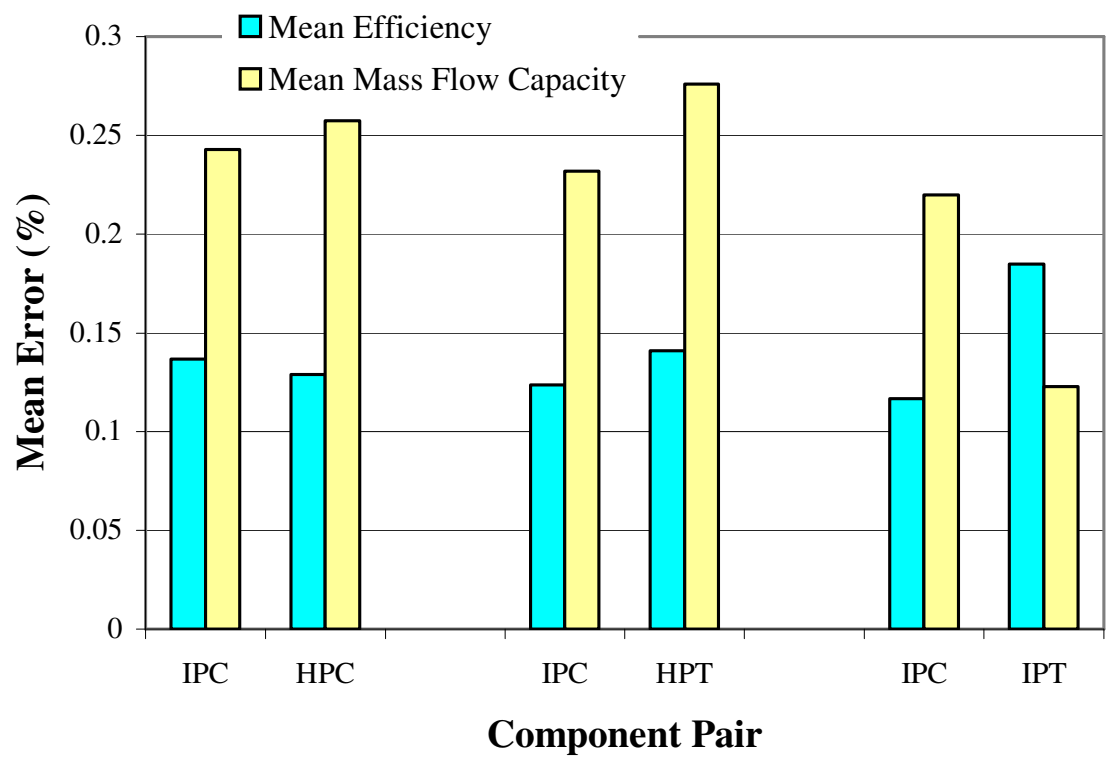

Figure 6 - Double-component network performance summary

- Mean error

- 1000 epochs/20_20_4/DCF approximation/SCG

The proposed magnitudes of the engine deteriorations have already been mentioned. However, during the process of assembling the 8668 combinations of efficiency and mass flow capacity for both chosen components, the planned combined magnitudes of the deviations were not included. Table 6 gives the planned magnitudes and the corresponding maximum values. It would have been desirable to include the planned values, however, the actual values used are equally as valid. For instance, it is just as likely that one component will suffer more degradations than its partner, in the chosen pairs, as it would be that both should suffer the same degree of damage.

Table 6 - Planned and actual double-component independent parameter deviations

\begin{tabular}{|c|c|c|c|c|c|}
\hline Component Pair & \multirow{2}{*}{$\begin{array}{c}\text { Deviation } \\
\text { Combination } \\
\text { Comp1 + Comp2 }\end{array}$} & \multicolumn{2}{|c|}{ Component 1 Deviations } & \multicolumn{2}{|c|}{ Component 2 Deviations } \\
\cline { 3 - 6 } & Description & $\%(\Delta \eta)$ & $\%(\Delta \Gamma)$ & $\%(\Delta \eta)$ & $\%(\Delta \Gamma)$ \\
\hline
\end{tabular}




\begin{tabular}{|c|c|c|c|c|c|}
\hline \multirow{3}{*}{ IPC + HPC } & Planned & -5 & -15 & -3 & -9 \\
\cline { 2 - 6 } & Actual 1 & -5 & -15 & -0.5 & -1 \\
\cline { 2 - 6 } & Actual 2 & -0.5 & -15 & -3 & -9 \\
\hline \multirow{3}{*}{ IPC + HPT } & Planned & -5 & -15 & -5 & +10 \\
\cline { 2 - 6 } & Actual 1 & -5 & -15 & -0.5 & +1 \\
\cline { 2 - 6 } & Actual 2 & -0.5 & -15 & -5 & +10 \\
\hline \multirow{3}{*}{ IPC + IPT } & Planned & -5 & -15 & -2.5 & +5 \\
\cline { 2 - 6 } & Actual 1 & -5 & -15 & -0.5 & +1 \\
\cline { 2 - 6 } & Actual 2 & -4.5 & -1 & -2.5 & +5 \\
\hline
\end{tabular}

It is worth noting again that the ratio of deterioration for each of the component's independent parameters is equally important to the relative magnitudes. The ratio of efficiency to mass flow capacity for component 1 of all the pairs in the 'Actual 1' case remains as 1:3, which represents compressor fouling [6]. The same ratio for component 2 of the IPC+HPT and IPC+IPT pairs in the 'Actual 1' case is 1:2, which is the same ratio as the planned value. A ratio of 1:2 for a turbine represents erosion [6]. Finally, the only discrepancy is that for component 2 of the IPC+HPC pair, the ratio is 1:2 rather than the planned 1:3.

For the 'Actual 2' case that refers to the correct maximum deviations for component 2 for all pairs, unfortunately, all the deviations for component 1 for all pairs were not as planned. Although, as has already been discussed, there are many combinations of efficiency and mass flow capacity, the ratios for the component 1, 'Actual 2' case for all pairs do not represent any particular engine degradation regime such as fouling or erosion.

As a footnote to these observations, it should be noted that the two 'actual' combinations quoted are only 2 of the possible 8668 combinations. However, they do represent the two combinations that include the maximum deteriorations of either component 1 or component 2. 


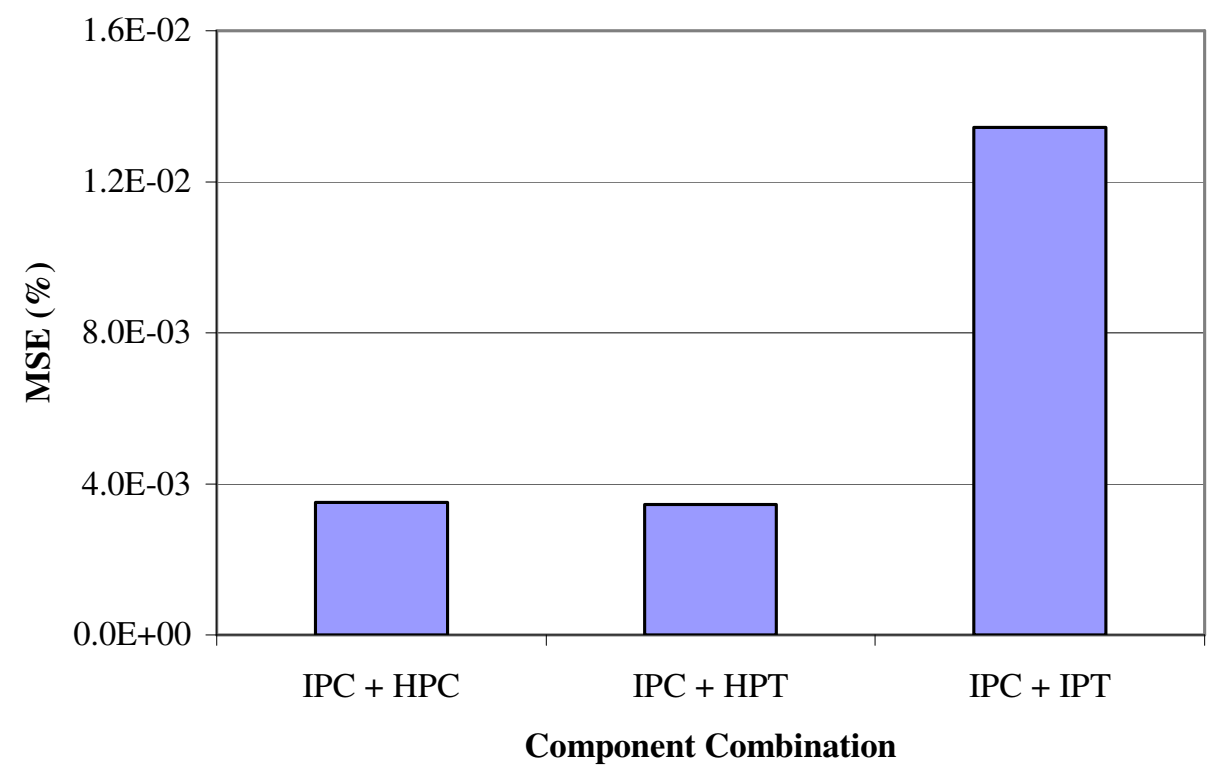

Figure 7 - Double-component network performance summary - Mean square error

The aim of an approximation ANN, or fault approximation ANN, is for it to be able to approximate an output based on a set of received data. Furthermore, the output produced by the ANN occurs after it has been trained with a set of pertinent data; typical errors introduced during training are shown in Figure 7. It was therefore useful to assess how well the test target and the actual output were correlated. Initially, the challenge of assessing the correlation of 8668 data sets was considered. It was decided to choose 200 data sets at each of the beginning, middle and end of the 8668 range: the 200 data set choice and that of the 3 samples were both arbitrary decisions. For example, the correlations for the IPC + HPC combinations for the data sets $1 \rightarrow 200$ and $8468 \rightarrow 8668$ are shown in Figures 8 to 11 . It should be noted that a network, described as 11-20-20-4, implies a structure with 11 input measurements, 20 neurons in each hidden layer, and four output possibilities. Because the number of input measurements is fixed, sometimes it may not be included in the network definition.

Overall the results show a reasonably good correlation between 'test target' and 'test actual' data. For the efficiency plots, there is a consistently good correlation with only some scatter for the IPC. The mass-flow capacity correlates well with the target apart from some scatter for the IPC plots for the first 200 data sets.

Having completed a correlation assessment using the above technique, another alternative method was identified. This second method utilised a mathematical function called the coefficient of correlation and a summary for the component pairs is shown in Figure 12. The second method allowed a single number to be quoted as a measure of performance. For instance, the coefficient of correlation for the IPC+HPC pairing IPC efficiency was approximately $99.98 \%$. The worst performer was the IPT efficiency for the IPC+IPT component pair. 


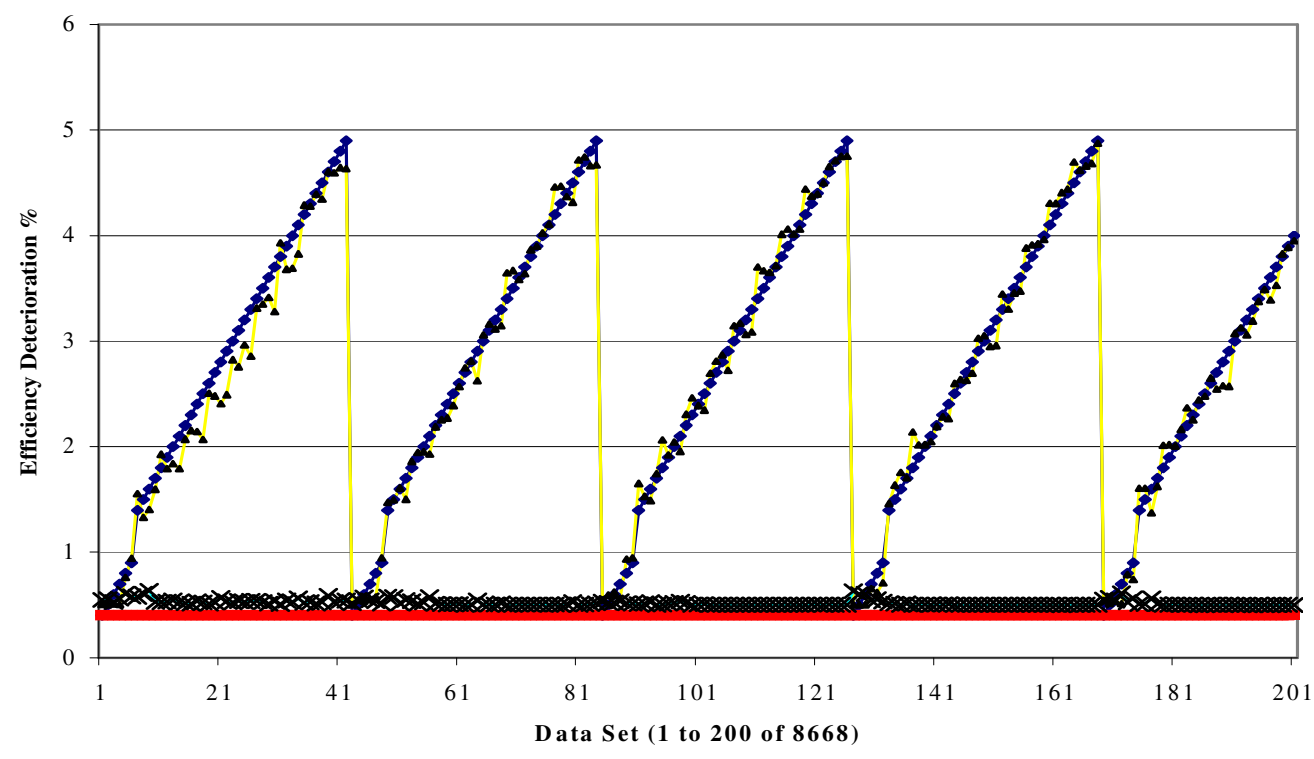

$\longrightarrow$ IPC Test Target $\longrightarrow$ HPC Test Target $\longrightarrow$ IPC Test Actual $\longrightarrow$ HPC Test Actual

Figure 8 - Network test performance

- IPC + HPC (data set 1-200)

- 1276 epochs/20_20_4/IPC+HPC/SCG

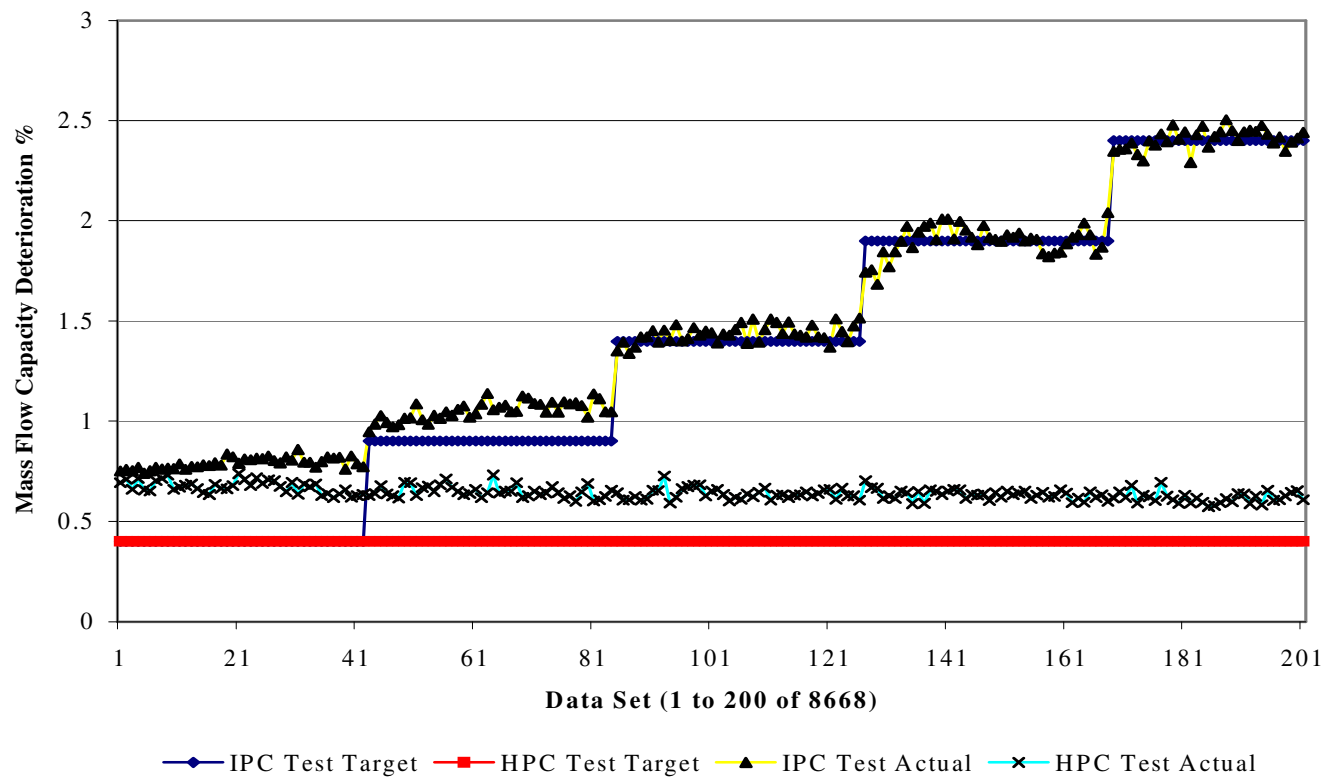

Figure 9 - Network test performance

- IPC + HPC (data set 1-200)

- 1276 epochs/20_20_4/IPC+HPC/SCG 


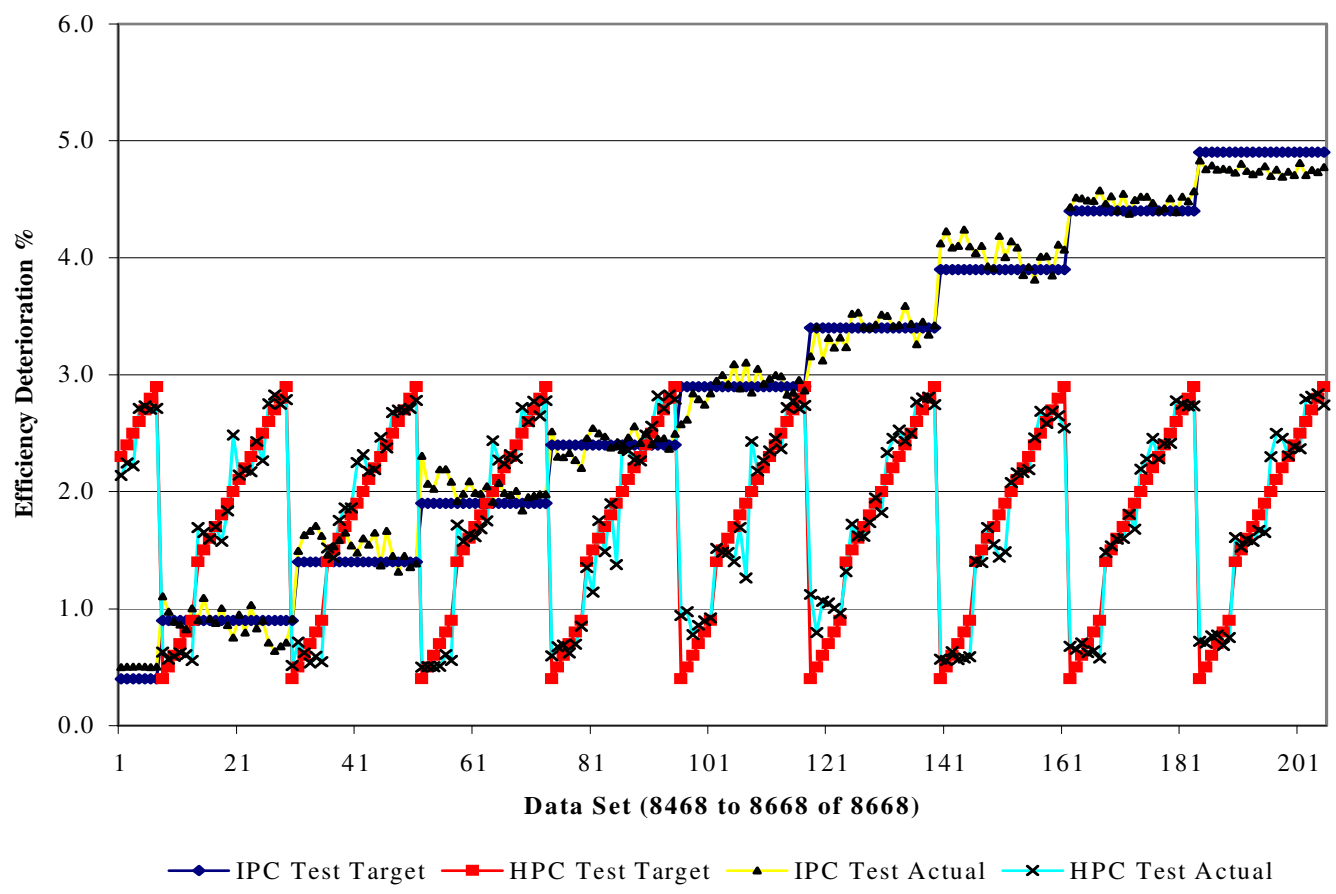

Figure 10 - Network test performance

- IPC + HPC (data sets 8468-8668)

- 1276 epochs/20_20_4/IPC+HPC/SCG

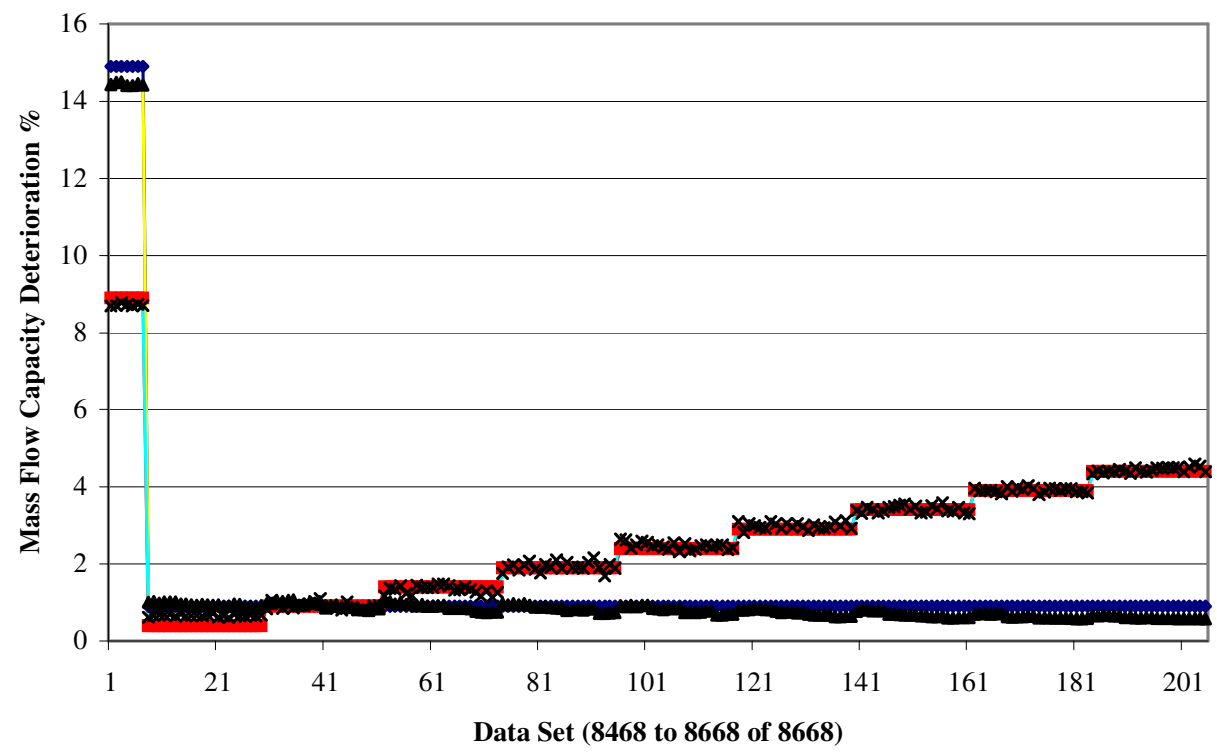

$\rightarrow$ IPC Test Target $\rightarrow-$ HPC Test Target - IPC Test Actual $\boldsymbol{x}$-HPC Test Actual

Figure 11 - Network test performance

- IPC + HPC (data sets 8468-8668)

- 1276 epochs/20_20_4/IPC+HPC/SCG 


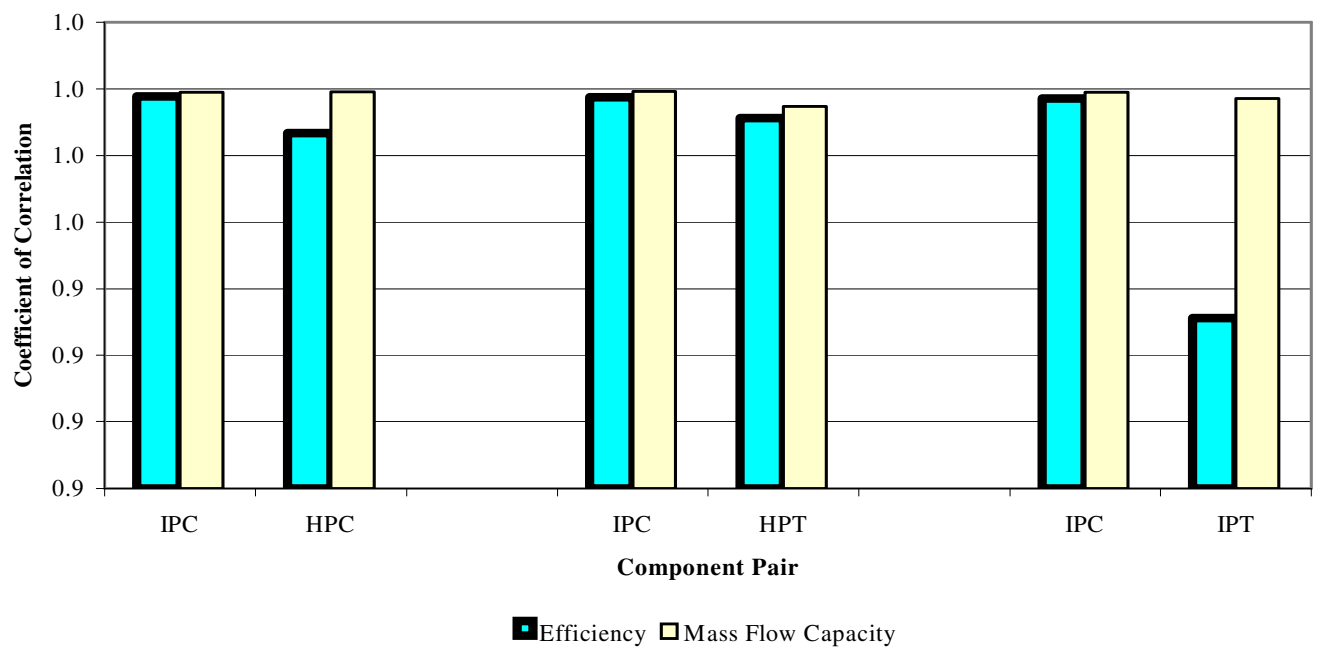

Figure 12 - Coefficient of correlation for DCF approximation -1000 epochs/20_20_4/DCF/SCG

The data used to train and test the 3 individual ANNs were used for an ANN with 3 outputs. The purpose of this was to have a DCF network that could identify the faultycomponent pair. The training and testing was again straightforward and the results encouraging, since, as for the SCF diagnostic network, the mean errors were negligible.

Figures 13 and 14 illustrate the frequencies of occurrence of the actual range of test errors. The IPC efficiency plot showed that the mean percentage test error was just under 0.13. Deductions from the IPC mass-flow capacity plot were far less conclusive, with a large spread percentage test error of between just over zero up to 0.15 .

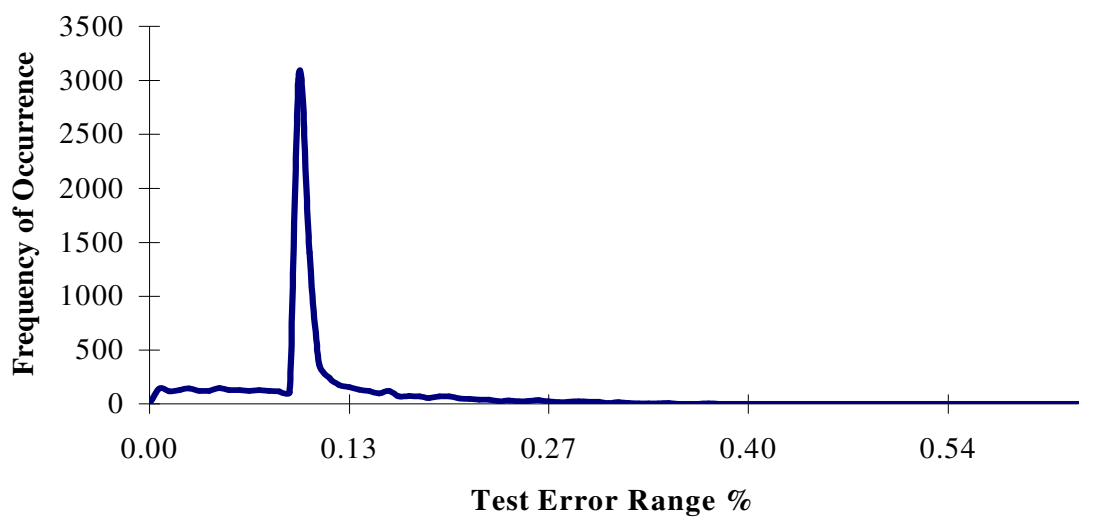

Figure 13 - Test error range for IPC efficiency

- 1276 epochs/20_20_4/IPC+HPC Approx/SCG 


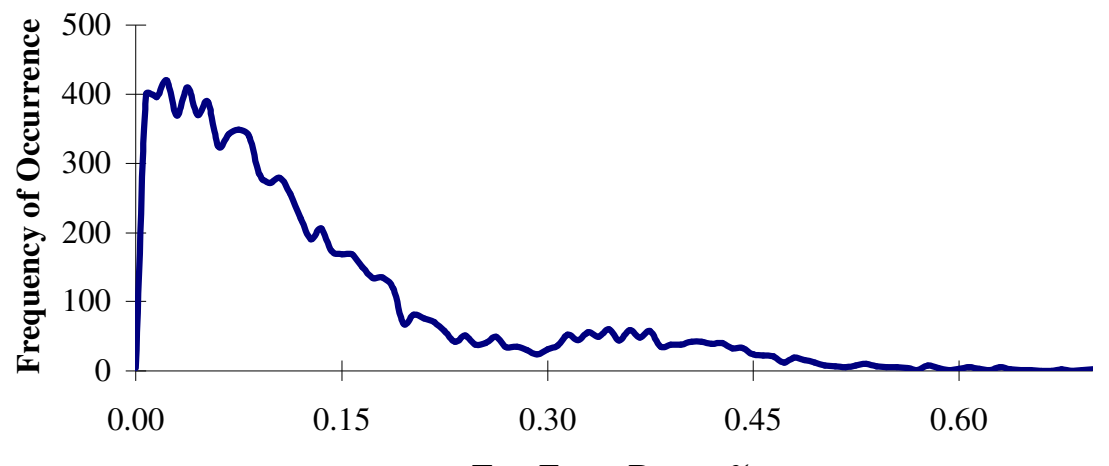

Test Error Range \%

\section{Figure 14 - Test error range for IPC flow capacity - 1276 epochs/20_20_4/IPC+HPC Approx/SCG}

\section{Discussion}

The results obtained for the double-component faults highlighted some general observations concerning the feasibility of networks for diagnostics. Regardless of which components were paired, each engine component had an individual network performance. For instance, the IPC was in each of the pairs, but had an almost constant standard deviation, mean error and coefficient of correlation regardless of the chosen partner. The absolute values for the previously mentioned parameters were valid only for the deteriorated data-set generated. It was not, however, possible to verify that this constant performance held true for all the components, since not all the pair combinations were investigated.

The actual deteriorated data generated, i.e. 8668 sets for the double-components, incorporated a large degree of randomness. Close inspection of the efficiencies and mass flow capacities chosen revealed that, although there were logical trends, the actual values were random. The assessment of the network performance, therefore, was conducted with the assumption of random deterioration. Such an assumption would model realistically the effects of real-life engine deteriorations, but it was noted that a full network performance assessment should also include an entirely non-randomly generated data-set.

The optimal network structure used was 2 hidden layers of 20 neurons and an output layer of 4 neurons, i.e. the 20_20_4 structure. The network structure was only one of several criteria that needed to be considered. It would have been less objective to assess the operation of the networks by quoting only one of the criteria, namely: the structure details; MSE; mean error, standard deviation for the test or coefficient of correlation.

From a practical point-of-view, the above statements clarified the notion that the use of ANNs has an arbitrary aspect to them. It was clear that much more investigation would be needed before a realistic view of the feasibility of ANNs for the present applicationcould be offered. 
The data in Table 7 summarise the errors produced for a selection of engine deterioration combinations. For all of the approximation cases, the absolute errors were identified. Those highlighted represent the worst two for each case, i.e. single- and double-component faults. In particular, the peak errors for the SCF networks were about double the peak errors for the DCF networks. The results showed that for the network design chosen and the constraints applied, the errors were high. For instance an absolute error of 1.56 for the IPC represents a $12.5 \%$ variation on the target value.

Table 7 - Results for single and double-component fault/approximation networks

\begin{tabular}{|c|c|c|c|c|c|c|c|c|c|c|c|c|}
\hline \multirow{3}{*}{ Components } & \multicolumn{4}{|c|}{ Implanted Fault (\%) } & \multicolumn{4}{|c|}{ Predicted Fault (\%) } & \multicolumn{4}{|c|}{$\begin{array}{c}\text { Absolute } \\
\text { Estimation Error }\end{array}$} \\
\hline & \multicolumn{2}{|c|}{ Component 1} & \multicolumn{2}{|c|}{ Component 2} & \multicolumn{2}{|c|}{ Component 1} & \multicolumn{2}{|c|}{ Component 2} & \multicolumn{2}{|c|}{ Component 1} & \multicolumn{2}{|c|}{ Component 2} \\
\hline & $\eta$ & $\Gamma$ & $\eta$ & $\Gamma$ & $\eta$ & $\Gamma$ & $\eta$ & $\Gamma$ & $\eta$ & $\Gamma$ & $\eta$ & $\Gamma$ \\
\hline Fan & -5 & -12.5 & - & - & -4.98 & -12.37 & - & - & 0.02 & 0.13 & - & - \\
\hline IPC & -5 & -12.5 & - & - & -4.99 & -14.06 & - & - & 0.1 & 1.56 & - & - \\
\hline HPC & -5 & -12.5 & - & - & -4.11 & -12.16 & - & - & 0.89 & 0.34 & - & - \\
\hline HPT & -5 & +12.5 & - & - & -4.99 & +11.42 & - & - & 0.01 & 1.08 & - & - \\
\hline IPT & -5 & +12.5 & - & - & -4.94 & +12.16 & - & - & 0.06 & 0.34 & - & - \\
\hline LPT & -5 & +12.5 & - & - & -4.99 & +12.06 & - & - & 0.01 & 0.44 & - & - \\
\hline IPC+HPC & -5 & -15 & -0.5 & -1 & -4.65 & -14.48 & -0.5 & -0.88 & 0.35 & 0.52 & 0 & 0.12 \\
\hline IPC+HPT & -5 & -15 & -0.5 & +1 & -4.81 & -14.61 & -0.5 & +0.74 & 0.19 & 0.39 & 0 & 0.26 \\
\hline IPC+IPT & -5 & -15 & -0.5 & +1 & -4.83 & -14.59 & $\begin{array}{c}- \\
0.49\end{array}$ & +0.86 & 0.17 & 0.41 & 0.01 & 0.14 \\
\hline
\end{tabular}

It would, however, be prudent to conduct an investigation into the relationship between target data selection and resultant errors. For instance, altering the training data by a small arbitrary amount generated the target data, but it might be possible to influence the test performance by changing the test-data generation procedure.

Reference to Table 7 would suggest that the performance of the DCF approximation networks was far better than for the SCF approximation networks. However, on balance, the results for the SCFs are better, which as discussed already was not expected.

The coefficient of correlation was used as one of the methods for assessing ANN performance. This means of assessment was just as useful for the component pairs as it was for the single-components. In addition, just as for the single-components, it was 
used most effectively in conjunction with other means of assessment like mean error and standard deviation.

The performance of an approximation ANN can be reduced by as much as $3 \%$ due to the loss, or degradation, of a sensor [4]. All the results obtained were not subject to any kind of sensor fault or degradation. Given that the data sets used included 11 dependent parameters, the probability of either sensor failure or degradation would in reality be fairly high. It would be reasonable to suggest that the probability of sensor problems would be a direct function of the number of sensors. The results lacked a degree of credibility that could have been provided by considering sensor faults. Future studies should therefore include this aspect of ANN assessment.

\section{Conclusions}

From the double-component fault approximation investigation, it can be concluded that:

1. The average standard deviation was similar, if not slightly better, than for the single-component faults; in reality the ANN error would rise with an increase in the number of engine components considered.

2. Generally the ANN performance for the double engine-component faults was good and the ANN for the IPC+HPC pair performed marginally better than for the other 2 pairs.

\section{References}

[1] Li, I Y. (2002). Performance-Analysis-Based Gas-turbine Diagnostics: a Review. Journal of Power and Energy, Vol 216 Part A, IMechE. Pages 363-377

[2] Friend, R. (2000). A Probabilistic, Diagnostic and Prognostic System for Engine Health and Usage Management. Aeropsace Conference Proceedings, 2000 IEEE, Volume 6, 18-25 March 2000, Pages 185-192.

[3] Green, Andrew J. (1998). The Development of Engine-Health Monitoring for Gas-turbine Engine Health and Life Management. AIAA 98-3544, $34^{\text {th }}$ AIAA/ASME/SAE/ASEE Joint Propulsion Conference \& Exhibition, Cleveland, Ohio, USA, 13-15 July 1998,.

[4] Alcock, A. MSc Thesis (2002). Application of Artificial Neural networks for Fault Diagnosis of Military Turbofan-Engines. Cranfield University, UK.

[5] Theriault, P G. MSc Thesis (2002). Application of Artificial Neural networks to the Fault Diagnosis of a Military Turbofan-Engine. Cranfield University, UK.

[6] Escher, P C. PhD Thesis (1995). Gas-turbine Engine and Sensor Fault Diagnosis. Cranfield University, UK. 
[7] Powrie, H E G and Fisher, C E. (1999). Engine-Health Monitoring: Towards Total Prognostics. Aeropsace Conference Proceedings, March 1999 IEEE, Volume 3, 6-13 Pages 11-20.

[8] Warwick, T. (1981). Overview of ARP 1587 Aircraft Gas-turbine EngineMonitoring System Guide. SAE Aircraft Gas-turbine Engine Monitoring Systems SP478, Aerospace Congress \& Exposition, Los Angeles Convention Center, California, USA, 13-16 October 1980.

[9] Smith, L. (2002). An Introduction to Neural Networks. http://www.cs.stir.ac.uk/ lss/NNIntro/InvSlides.html. University of Stirling.

[10] Ogaji S, Li Y G, Sampath S and Singh R. (2003). Gas-path Fault Diagnosis of a Turbofan Engine from Transient Data Using Artificial Neural networks (GT200338423). ASME Turbo Expo, Atlanta, Georgia, USA, 16-19 June 2003.

[11] Cruz,C. (1991). Understanding Neural networks: A Primer. Clutter Information Corps, USA. ISBN 0-943-779-693.

[12] Mathworks (2003). Matlab Manual.

[13] Winston, P H. (1992). Artificial Intelligence $-3^{\text {rd }}$ Edition. Addison-Wesley Publishing Company. ISBN 0-201-53377-4.

[14] Ogaji, S and Singh, R. (2002). Study of the Optimisation of Measurement Sets for Gas-path Fault Diagnosis in Gas-turbines. ASME Turbo Expo, Amsterdam, The Netherlands, 3-6 June 2002, 